\title{
GAMBARAN KOMPLIKASI POST ODONTEKTOMI GIGI IMPAKSI MOLAR KETIGA RAHANG BAWAH TAHUN 2018 DI RSGM X BANDUNG
}

\author{
Neng Vivie Agustina Puspitasari ${ }^{1}$, Borman Sumaji ${ }^{2}$, Natallia Pranata ${ }^{3 *}$ \\ ${ }^{1}$ Fakultas Kedokteran Gigi, Universitas Kristen Maranatha \\ ${ }^{2}$ Departemen Bedah Mulut, Fakultas Kedokteran Gigi, Universitas Kristen \\ Maranatha \\ ${ }^{3}$ Departemen Oral Biology, Fakultas Kedokteran Gigi, Universitas Kristen \\ Maranatha
}

*email: natallia.pranata@dent.maranatha.edu

\begin{abstract}
Abstrak
Perkembangan dan pertumbuhan gigi sering mengalami gangguan pada saat erupsi. Gigi yang tidak berhasil erupsi dengan sempurna dan terpendam dalam rahang dengan posisi yang abnormal disebut impaksi. Frekuensi impaksi gigi yang paling sering terjadi adalah gigi molar ketiga rahang bawah.

Impaksi gigi molar ketiga rahang bawah juga dapat mengganggu proses pengunyahan dan sering menyebabkan berbagai komplikasi, maka dari itu diperlukan pencabutan. Upaya mengeluarkan gigi impaksi terutama pada molar ketiga rahang bawah dilakukan dengan tindakan pembedahan yang disebut dengan odontektomi. Tujuan dari penelitian ini adalah mendapatkan informasi gambaran komplikasi pada pasien yang telah dilakukan odontektomi di RSGM X Bandung.

Penelitian ini merupakan jenis penelitian observational yang dirancang secara deskriptif dengan metode cross sectional dan pengambilan data secara retrospektif. Pengambilan data Rekam Medis pasien pada Januari - Desember 2018 di RSGM X Bandung dengan hari kontrol pada hari ke 7.

Hasil penelitian ini terdapat beberapa komplikasi post odontektomi gigi molar ketiga rahang bawah seperti trismus $1,62 \%$, bengkak $4,22 \%$, parestesia $0,32 \%$, dry socket $1,94 \%$, perdarahan $1,62 \%$, sakit $17,2 \%$, fraktur $0 \%$.

Komplikasi post odontektomi yang terjadi di RSGM X Bandung pada hari kontrol hari ke 7 setelah dilakukan odontektomi sebanyak $25,5 \%$.
\end{abstract}

Kata kunci: Odontektomi, impaksi, molar ketiga rahang bawah, komplikasi 


\title{
THE OVERVIEW OF POST ODONTECTOMY COMPLICATIONS OF LOWER MOLAR THIRD IMPACTION TEETH IN 2018 AT X RSGM BANDUNG
}

\begin{abstract}
The development and growth of teeth often experience interference when erupted. Teeth that do not erupt successfully and are buried deep in the jaw in an abnormal position are called impaction. The most common tooth impaction frequency is the lower third molar.

Impacted mandibular third molars can also interfere with the mastication process and often cause various complications, and therefore revocation is needed. Efforts to remove impacted teeth, especially in the mandibular third molar, are carried out with a surgical procedure called odontectomy. The purpose of this study was to obtain information about complications in patients who had performed odontectomy at RSGM X Bandung.

This research is an observational study that was designed descriptively with cross sectional method and retrospective data collection. Retrieval of patient Medical Record data in January - December 2018 at RSGM X Bandung with control day on day 7.

The results of this study were several post odontectomy complications of lower third molar teeth such as trismus $1.62 \%$, swelling $4.22 \%$, paresthesias $0.32 \%$, dry socket $1.94 \%$, bleeding $1.62 \%$, pain $17.2 \%$, $0 \%$ fracture.

Post odontectomy complications that occurred at RSGM X Bandung on control day 7 after odontectomy were $25.5 \%$.
\end{abstract}

Keywords: Odontectomy, impaction, mandibular third molars, complications 


\section{Pendahuluan}

Perkembangan dan pertumbuhan gigi sering mengalami gangguan pada saat erupsi. Gigi yang tidak berhasil erupsi dengan sempurna dan terpendam dalam rahang dengan posisi yang abnormal disebut impaksi. Frekuensi impaksi gigi yang paling sering terjadi adalah gigi molar ketiga rahang bawah. ${ }^{1,2,3}$

Impaksi gigi molar ketiga rahang bawah juga dapat mengganggu proses pengunyahan dan sering menyebabkan berbagai komplikasi. Komplikasi yang diakibatkan oleh gigi impaksi maka diperlukan pencabutan. Upaya mengeluarkan gigi impaksi terutama pada molar ketiga rahang bawah dilakukan dengan tindakan pembedahan yang disebut dengan odontektomi. ${ }^{1,4}$

Tindakan odontektomi dapat mengakibatkan terjadinya komplikasi. Berdasarkan beberapa penelitian komplikasi odontektomi cukup tinggi berkisar 2,6\% hingga 30,9\%. Komplikasi odontektomi yang paling sering terjadi antara lain seperti trismus 0\%-37\%, dry socket 0,5$68,4 \%$, pembengkakan $37.5 \%$, parestesia $0,1 \%-22 \%$, fraktur mandibula $0.049 \%$, perdarahan 0,2\%-5.8\%, dan sakit 37,7\%. Adapun faktor-faktor yang mempengaruhi terjadinya komplikasi, seperti usia dan kondisi kesehatan pasien, jenis kelamin, tingkat kesulitan gigi, pengalaman ahli bedah, merokok, kualitas kebersihan mulut, dan teknik bedah. Secara keseluruhan insidensi komplikasi dan tingkat keparahan komplikasi ini berkaitan langsung dengan kedalaman impaksi dan usia pasien. $5,6,7$

Berdasarkan data dari RSGM X Bandung, sejak tahun 2015 terdapat 99 pasien odontektomi dan terus meningkat hingga tahun 2018 yaitu 426 pasien. Peningkatan prevalensi impaksi gigi molar ketiga rahang bawah mengakibatkan frekuensi odontektomi meningkat sehingga memungkinkan untuk terjadinya komplikasi. Penelitian tentang gambaran komplikasi pada pasien yang telah dilakukan odontektomi gigi molar ketiga rahang bawah di RSGM X Bandung belum pernah dilakukan, maka penelitian ini dilakukan dengan tujuan untuk mengetahui tingkat komplikasi yang terjadi pasca odontektomi gigi molar ketiga di RSGM $\mathrm{X}$ Bandung yang dapat dijadikan bahan pertimbangan dalam pencegahan terjadinya komplikasi yang lebih berat dan bisa digunakan sebagai tolak ukur untuk meningkatkan kualitas pelayanan kesehatan pada umumnya.

\section{Metode Penelitian}

Penelitian ini merupakan jenis penelitian observational yang dirancang secara deskriptif dengan metode cross sectional dan pengambilan data secara retrospektif. Pengambilan data 
Rekam Medis pasien pada Januari - Desember 2018 di RSGM X Bandung. ${ }^{8}$

Populasi dalam penelitian ini adalah seluruh pasien yang telah dilakukan odontektomi gigi molar ketiga rahang bawah di RSGM X Bandung. Dari hasil penelitian pendahuluan, data terbanyak dilakukan odontektomi di RSGM X Bandung pada tahun 2018 dari bulan Januari sampai Desember yaitu sebanyak 426 pasien.

Teknik pengambilan sampel pada penelitian ini adalah purposive sampling. Purposive sampling adalah teknik penentuan sampel dengan pertimbangan tertentu. Dimana sampel yang diambil adalah sampel yang sesuai dengan kriteria inklusi. ${ }^{8}$

Alat dan bahan yang dipergunakan dalam penelitian ini: Rekam medis yang diambil adalah rekam medis pasien yang telah dilakukan tindakan odontektomi gigi molar ketiga rahang bawah periode Januari-Desember 2018 di RSGM X Bandung; Alat tulis; dan Lembar kerja.

Teknik pengumpulan data yaitu dengan menggunakan data sekunder. Data diperoleh dengan mengumpulkan semua data pasien yang mengalami komplikasi dari rekam medik pasien dari bulan Januari-Desember 2018 dengan menggunakan lembar kerja.

Data yang telah terkumpul akan dianalisa dan dijadikan persentase data sesuai dengan kelompok komplikasi yang terjadi dan akan disajikan dalam bentuk diagram pie.

\section{Hasil Penelitian}

Pada penelitian ini dilakukan pada bulan Mei sampai Juni 2019, didapatkan 426 data pasien yang dilakukan odontektomi gigi impaksi molar ketiga rahang bawah. Data yang dipakai pada penelitian ini berjumlah 302 data, sedangkan data yang lainnya didapatkan data yang tidak lengkap sehingga tidak dapat dipakai yaitu sebanyak 124 data.

\section{Tabel 1. Data Pasien Odontektomi}

\begin{tabular}{lc}
\hline Nama data & Jumlah \\
\hline & \\
Trtal data dipakai & $42 \hbar$ \\
Data yang dipak dipakai & 302 \\
Data yang tidak komplikasi & 124 \\
Pasien dengan komplisi baik & 77 \\
Pasien dengan kondisi & 225 \\
\hline
\end{tabular}

Komplikasi post odontektomi di RSGM X Bandung periode Januari sampai Desember 2018 dengan hari kontrol pada hari ke 7 terdapat sebanyak 77 pasien yaitu $25,5 \%$, sedangkan pasien 
dengan kondisi baik terdapat 225 pasien yaitu 74,5\%, ini sesuai dengan penelitian sebelumnya yang menyatakan bahwa komplikasi post odontektomi dapat terjadi berkisar 2,6\% - 30,9\%.

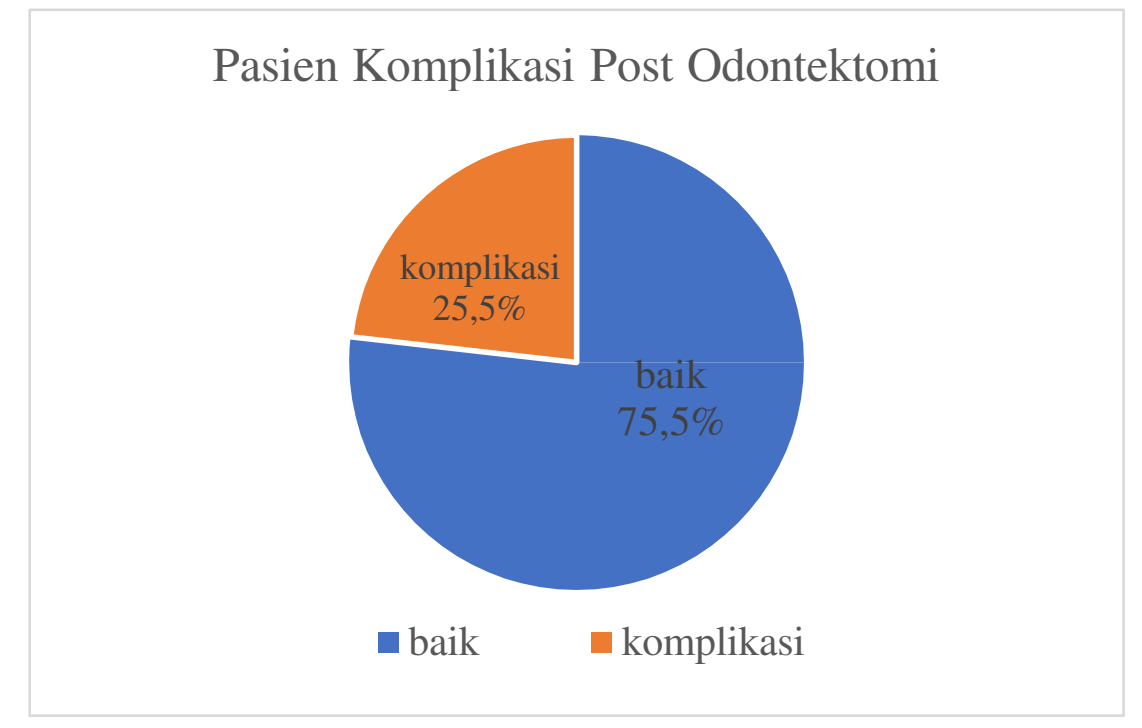

\section{Gambar 1. Jumlah Pasien yang Mengalami Komplikasi dan Pasien Dengan Kondisi Baik}

Berdasarkan dari hasil penelitian ini, dari 77 pasien terdapat 13 pasien dengan dua komplikasi yang bersamaan yaitu bengkak disertai dengan sakit, sehingga terdapat perbedaan jumlah antara jumlah pasien dengan jumlah komplikasi post odontektomi berdasarkan kasus, dimana jumlah komplikasi post odontektomi gigi molar ketiga rahang bawah berdasarkan kasus terdapat 83 kasus dari total kasus yang ada. Berikut adalah data pasien yang mengalami komplikasi seperti trismus, pembengkakkan, parestesia, dry socket (alveolar osteitis), sakit, pendarahan, dan fraktur mandibula yaitu sebagai berikut:

Tabel 2. Komplikasi Post Odontektomi Gigi M3 RB Berdasarkan Kasus

\begin{tabular}{lclc}
\hline \multicolumn{1}{c}{ Komplikasi } & Jumlah & Kelas & Persentase \\
\hline Trismus & 5 & I dan II & $1,62 \%$ \\
Bengkak & 13 & I dan II & $4,22 \%$ \\
Parestesia & 1 & II & $0,32 \%$ \\
Dry Socket & 6 & I dan II & $1,94 \%$ \\
Pendarahan & 5 & I dan II & $1,62 \%$ \\
Sakit & 53 & I dan II & $17,2 \%$ \\
Fraktur Mandibula & 0 & - & $0 \%$ \\
\hline
\end{tabular}




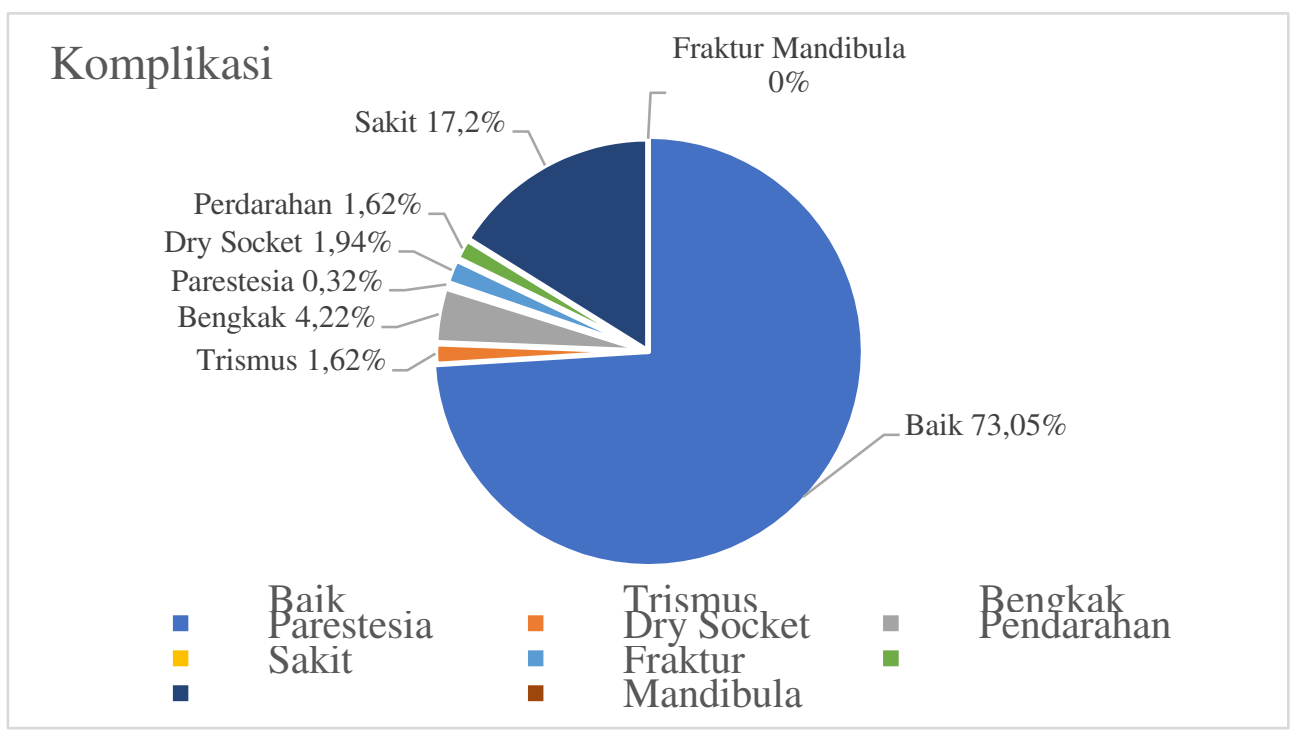

\section{Gambar 2. Data Komplikasi Post Odontektomi Gigi Impaksi Molar Ketiga Rahang Bawah di RSGM X Bandung}

\section{Pembahasan}

Berdasarkan penelitian pasien yang mengalami komplikasi terdapat 77 pasien dari total 302 pasien. Dari 77 pasien komplikasi yang paling sering terjadi di RSGM X Bandung adalah sakit $17,2 \%$ dan bengkak 4,22\% dimana komplikasi ini tergolong komplikasi yang ringan dan normal dari tindakan odontektomi gigi impaksi molar ketiga rahang bawah. ${ }^{9}$ Sedangkan komplikasi yang paling jarang terjadi yaitu parestesia $0,32 \%$ dan fraktur mandibular $0 \%$.

Odontektomi sebaiknya dilakukan pada saat pasien masih muda, yaitu pada usia 2526 tahun sebagai tindakan profilaktik atau pencegahan terhadap terjadinya patologi. Odontektomi lebih mudah dilakukan pada pasien usia muda dimana mahkota gigi baru terbentuk dan apeks gigi belum terbentuk dengan sempurna. Selain itu, jaringan tulang di sekitar gigi pun masih lunak trauma pembedahan minimal dan tidak mencederai nervus atau jaringan sekitar. Odontektomi pada pasien diatas 40 tahun, penyembuhan luka akan lebih lama yang disebabkan oleh trauma pembedahan yang lebih besar, ini dapat terjadi karena pada usia pasien yang lebih tua sudah terjadi mineralisasi tulang dimana tulangnya sudah sangat kompak dan kurang 
elastis, celah ligamen periodontium/folikular mengecil atau tidak ada, dan juga sudah terjadi ankilosis gigi pada soketnya. ${ }^{10,11}$

Komplikasi yang terjadi juga bergantung pada reaksi individual. Secara umum semakin dalam letak gigi impaksi dan semakin banyak tulang yang menutupinya serta makin besar penyimpangan angulasi gigi impaksi dari kesejajaran terhadap sumbu molar kedua, makin sulit

pencabutannya. Komplikasi post odontektomi yang paling sering terjadi adalah edema disertai dengan nyeri. Komplikasi lainnya berupa edema, sakit, trismus, paresthesia, dry socket, pendarahan dan yang lebih parah seperti fraktur mandibula.

Rasa sakit pasca bedah adalah hal yang normal. Sakit dimulai ketika efek anestesi lokal mereda dan mencapai intensitas maksimal selama 12 jam pertama pasca operasi. Pada penelitian ini terdapat 53 pasien atau sebesar 17,2\% yang merasa sakit setelah dilakukan odontektomi. Berbagai macam analgesik tersedia untuk manajemen nyeri pasca bedah. Analgesik yang paling umum adalah kombinasi asam asetilsalisilat atau asetaminofen dan analgesik antiinflamasi nonsteroid. Analgesik harus diberikan sebelum efek anestesi lokal mereda. Dengan cara ini, rasa sakit biasanya lebih mudah dikendalikan, membutuhkan lebih sedikit obat, dan mungkin memerlukan analgesik yang kurang kuat. pemberian antiinflamasi nonsteroid sebelum pembedahan mungkin bermanfaat dalam membantu mengontrol rasa sakit pasca operasi. ${ }^{12,13}$

Edema sebagai akibat trauma setempat seperti odontektomi terjadi sebagai tanda proses radang dengan disertai kemerahan dan rasa sakit. Pada penelitian ini pasien yang menderita edema terdapat 13 pasien atau sebanyak 4,22\% pada hari kontrol pada hari ke 7 post odontektomi. Menurut penelitian sebelumnya, edema yang terjadi post odontektomi berkisar pada angka 37,7\% pada hari setelah dilakukan odontektomi. Perbedaan ini disebabkan karena perbedaan hari kontrol, dimana penelitian sebelumnya kontrol pada hari ke 1 stelah tindakan odontektomi sedangkan penelitian ini memakai hari kontrol ke 7. Edema biasanya mencapai puncaknya pada akhir hari kedua pasca operasi dan biasanya menghilang pada hari kelima hingga ketujuh. Edema merupakan reaksi normal jaringan dari cedera pada setiap tindakan odontektomi. 6,12

Pada penelitian ini terdapat 5 pasien yang mengalami trismus atau sebanyak 
1,62\%. Ini sesuai dengan penelitian sebelumnya, dikatakan bahwa trismus dapat terjadi berkisar 0\%- 37,2\%. Trismus dievaluasi dengan jarak antara gigi seri tengah kanan atas dan bawah pada pembukaan mulut maksimum; modifikasi dari metode ini menghitung hasil bagi antara jarak pra operasi dan pasca operasi. Biasanya dikatakan trismus apabila ada perbedaan sebanyak $5 \mathrm{~mm}$. Trismus dapat disebabkan karena pasca bedah. Trismus dapat disebabkan oleh edema disekitar bekas pembedahan molar ketiga akan meyebabkan perubahan jaringan sekitarnya dan muskulus pengunyahan mengalami kontraksi sehingga akan menimbulkan trismus. Tetapi ada juga yang mengatakan bahwa trismus terjadi bukan karena meningkatnya volume dari muskulus karena edema dan infiltrate tetapi lebih disebabkan karena reaksi atas rasa sakit yang disebabkan oleh gerakan rahang. 1,6

Pembengkakan, nyeri, dan trismus dianggap sebagai komplikasi sementara dan diperkirakan akan terjadi pasca pembedahan. Meski sementara, kondisi ini dapat menjadi sumber kecemasan bagi pasien. ${ }^{14}$ Pada penelitian ini terdapat 1 pasien yang mengalami paresthesia atau $0,33 \%$. Parestesia sendiri terjadi karena adanya kerusakan nervus. Nervus yang paling sering cedera selama pencabutan dan pembedahan gigi adalah nervus alveolaris inferior dan nervus lingualis. Menurut penelitian sebelumnya, defisit neurosensori setelah odontektomi lebih rendah terjadi pada prevalensi $0,1 \%$ hingga $22 \%$ untuk defisit saraf lingual dan $0,26 \%$ hingga $8,4 \%$ untuk defisit saraf alveolar inferior. Dalam 4-8 minggu setelah operasi, $96 \%$ cedera saraf alveolar inferior pulih, dan tingkat pemulihan tidak dipengaruhi oleh jenis kelamin dan hanya sedikit berdasarkan usia. Pada penelitian ini pasien yang mengalami parestesia adalah perempuan dengan usia 37 tahun, dengan klasifikasi impaksi kelas II. Faktor risiko yang terkait dengan defisit neurosensorik permanen pada klasifikasi Pell dan Gregory IC atau klasifikasi impaksi IIC, dengan usia lebih dari 24 tahun, dan pada wanita. ${ }^{16}$ Sebagian besar parestesia oral disebabkan oleh trauma langsung yang terkait dengan prosedur bedah, seperti ekstraksi gigi atau bedah ortognatik. Namun, penelitian telah menunjukkan bahwa anestesi juga dapat terjadi setelah pembedahan gigi. 6,15

Perdarahan terdapat 5 pasien atau $1,62 \%$ dari total komplikasi yang terjadi di RSGM X Bandung, 4 pasien dengan klasifikasi impaksi kelas I dan satu pasien dengan klasifikasi kelas 
II. Pendarahan setelah tindakan odontektomi ini biasanya terjadi sampai 48 jam setelah pembedahan. Menurut penelitian sebelumnya, perdarahan ini terjadi sekitar $0,2 \%-5,8 \%$. Variasi anatomi, kedekatan gigi dengan ikatan saraf vaskular dari kanal mandibula, dan koagulopati adalah penyebab utama perdarahan. Cara yang paling efektif untuk mencapai hemostasis setelah operasi adalah dengan mengoleskan kasa langsung ke tempat operasi dengan tekanan yang memadai. Ini biasanya dilakukan dengan meminta pasien menggigit alas kain kasa. Dalam membandingkan perdarahan dengan jenis kelamin, usia, posisi gigi, klasifikasi gigi, retensi, sudut, kondisi sistemik, kebiasaan buruk, penggunaan kontrasepsi oral dan menstruasi, tidak ada perbedaan signifikan secara statistik. 6.13

Dry Socket / Alveolar osteitis dalam penelitian ini terdapat 6 pasien atau sekitar 1,94\% dengan klasifikasi impaksi kelas I dan II. Prevalensi dari dry socket dilaporkan berkisar $0,5 \%$ - 86,4\%. Dry socket ditandai oleh rasa sakit yang hebat dan berdenyut yang tidak dapat dikendalikan oleh pembunuh rasa sakit biasa, ini bisa dimulai antara hari kedua dan kelima setelah odontektomi, dengan bau yang tidak sedap dan tanpa jaringan yang tidak rusak di dalam soket. Beberapa peneliti mengklasifikasikan alveolitis sebagai nekrosis jaringan alveolar dengan tulang yang terbuka, dengan perpanjangan nyeri antara 5 dan 7 hari, bersifat neuralgik, intens atau berat. Beberapa factor resiko penggunaan kontrasepsi oral dan merokok dapat meningkatkan terjadinya dry socket. Kejadiannya dapat dikurangi dengan beberapa teknik, yang sebagian besar ditujukan untuk mengurangi kontaminasi bakteri di lokasi bedah. ${ }^{13,17}$

Pada pasien odontektomi di RSGM X Bandung tidak terdapat komplikasi seperti fraktur mandibular. Fraktur paling sering terjadi pada individu yang lebih tua dengan tulang yang padat, diperngaruhi oleh posisi molar ketiga, dan juga oleh tekanan dari operator pada saat melakukan elevasi dalam upya pengambilan gigi. Jika fraktur terjadi maka fiksasi internal dengan miniplates adalah pilihan yang sangat baik dalam situasi ini. Fiksasi kawat dan aplikasi fiksasi intermaxilarry adalah alternative yang dapat diterima. Fraktur mandibular yang terlambat biasanya terjadi 4 sampai 6 minggu setelah ekstraksi pada pasien yang lebih tua dari 40 tahun. 13

Penelitian ini tidak menghubungkan data komplikasi dengan usia, jenis 
SONDE (Sound of Dentistry) Vol 4 No 2

kelamin, tingkat kesulitan gigi ataupun factor resiko lainnya. Penelitian ini juga tidak menggunakan metode penelitian pemeriksaan secara langsung pada pasien.

\section{Simpulan}

Komplikasi post odontektomi yang terjadi di RSGM X Bandung pada hari kontrol ke 7 setelah dilakukan odontektomi terjadi sebanyak 83 kasus dengan rincian sebagai berikut: Trismus 1,62\%, bengkak 4,22\%, paresthesia 0,32\%, dry Socket $1,94 \%$, perdarahan $1,62 \%$, sakit $17,2 \%$, fraktur mandibula $0 \%$. 


\section{Daftar Pustaka}

1. Dwipayanti A, Adriatmoko W, Rochim A. Komplikasi post odontektomi gigi molar ketiga rahang bawah impaksi. J PDGI. 2009;58(2):20-24.

2. Santosh P. Impacted mandibular third molars: review of literature and a proposal of a combined clinical and radiological classification. Ann Med Health Sci Res. 2015;5(4):229234.

3. Fitri AM, Kasim A, Yuza AT. Impaksi gigi molar tiga rahang bawah dan sefalgia Mandibular third molar impaction and cephalgia. J Kedokt Gigi Univ Padjadjaran. 2016;28(3).

4. Saleh E, Prihartiningsih, Rahardjo. Odontektomi Gigi Molar Ketiga Mandibula Impaksi Ektopik dengan Kista Dentigerous secara Ekstraoral. Maj Kedokt Gigi Klin. 2015; Vol 1, No2:85-91. https://journal.ugm.ac.id/index.php/mkgk/article/viewFile/11956/8807.

5. Ahmed SS, ElSharrawy EA, Hamed TA. Clinical Evaluation of Cox-2 Inhibitor for Management of Post- Operative Complications after Odontectomy of Impacted Lower Third Molar. J Am Sci. 2014;10(11).

6. Deliverska EG, Petkova M. Complications After Extraction of Impacted Third Molars Literature Review. J IMAB - Annu Proceeding (Scientific Pap. 2016;22(3):1202-1211. doi:10.5272/jimab.2016223.1202

7. Agrawal A, Yadav A, Chandel S, Singh N, Singhal A. Wisdom tooth-complications in extraction. J Contemp Dent Pract. 2015;15(1):34-36. doi:10.5005/jp-journals-10024-1484

8. Sugiyono. Metode Penelitian Kuantitatif, Kualitatif, Dan R\&D. Bandung: CV Alfabeta; 2017.

9. Edwyn Saleh. Strategi dalam Mengurangi Komplikasi Odontektomi Gigi Molar Ketiga Bawah. 2006 jul;6(2)122-125

10. Malik N.A. Textbook of oral and maxillofacial surgery. $2^{\text {nd }}$ ed. New Delhi: Jaypee: 2008; 116-132.

11. Pedersen G.W. Buku Ajar Praktis Bedah Mulut (Oral Surgery), Alih Bahasa: Purwanto, Basoeseno. Jakarta: EGC; 2012. Hal 64-65

12. David W, Margaret J, Fehrenbach EM. Mosby's Dental Dictionary, 2nd edn St Louis. 2008.

13. Peterson LJ. Principles of Oral and Maxillofacial Surgery. $4^{\text {th }}$ ed. London: Hamilton; 2011: Hal 101-103

14. Ayaz H, Rehman AU, Din FU. Post-operative complications associated with impacted mandibular third molar removal. Pakistan Oral \& Dental Journal. 2012 Dec;32(3):389-392.

15. Garisto, Gabriella A. Gaffen, Andrew S. Lawrence, Herenia P. Tenenbaum, Howard C. 
Haas, Daniel A. Occurrence of Paresthesia After Dental Local Anesthetic Administration in the United States. The Journal of the American Dental Association. 2010; 141(7): 836844

16. Blondeau F, Daniel NG. Extraction of impacted mandibular third molars: postoperative complications and their risk factor. J Can Dent Assoc. 2007 May;73(4):325.

17. Azenha MR, Kato RB, Bueno RBL, Neto PJO, Ribeiro MC. Accidents and complications associated to third molar surgeries performed by dentistry students. Oral Maxillofac Surg. 2014 Dec;18(4):459-464. 